\title{
The problems of teacher candidates' and their psychological sympthoms
}

\section{Öğretmen adaylarının problem alanları ve psikolojik belirtileri}

\author{
Sefa Bulut ${ }^{1}$ \\ Musa Yildirim²
}

Özet

$\mathrm{Bu}$ çalışmanın amacı öğretmen adaylarının problem alanlarını tespit etmek ve öğretmen adaylarının yaşadığı psikolojik belirtilerin problem alanı, cinsiyet ve bölüm değişkenine göre farklılık gösterip göstermediğini incelemektir. Katilımcilarin $\quad 77(\% 63.6)$ 'sini kadinlar 44(\%36.4)'ünü erkekler oluşturmaktadır. Örneklem grubunun 55(\%45.5)'i Rehberlik ve Psikolojik Danışmanlik Bölümünde, 43(\%35.5)'ü Sınıf Öğretmenliği Bölümünde ve 23(\%19)'ü Bilgisayar ve Öğrenim Teknolojileri Eğitimi Bölümünde öğrenim görmektedir. Araştırmada ölçeme aracı olarak Belirti Tarama Listesi(SCL-90) ve Bilgi Formu kullanilmıştır. Elde edilen veriler SPSS 22.0 paket programinda değerlendirilmiştir. Elde edilen bulgular şu şekildedir; öğretmen adaylarının Belirti Tarama Listesinin(SCL-90) alt boyutlarından aldığ1 puanlar 1,56(OKB) ile .79 (Psikotizm) arasında değişmektedir. Bunun yanında öğretmen adaylarının yaşadığı problem alanlarından KPSS kaygisının ve gelecek kaygisının frekansları diğer alanların frekanslarından daha yüksektir. Son olarak psikolojik belirtilerin; cinsiyet, problem alanı ve bölüm değisskenine göre farklılık göstermediği görülmüsstür. Elde edilen bulgular alan yazın ışı̆̆ında tartı̧ılmıstır.

Anahtar Kelimeler: Öğrenci Sorunları, Gelecek Kayg1s1, Kpss Kaygis1, Psikolojik Belirtiler.

Keywords: Colloge Student's Problems, Future Anxiety, KPSS Anxiety, Psychological Sympthoms.

(Extended English summary is at the end of this document)

\footnotetext{
${ }^{1}$ Prof. Dr., İbn Haldun Üniversity, Department of Counseling Psychology, sefabulut22@gmail.com

2 M.A., musayildirim78@gmail.com
} 
Bulut, S., \& Yıldırım, M. (2020). Öğretmen adaylarının problem alanları ve psikolojik belirtileri. Journal of Human Sciences, 17(2), 402-414. doi:10.14687/jhs.v17i2.4313

\section{GİRİ̧̧}

Ülkemiz genç nüfusun yoğun olduğu bir ülkedir. Özellikle son yıllarda artan üniversite sayıs1 ile birlikte gençlerin yükseköğretime olan ilgisinin de arttı̆̆1 gözlenmektedir. Nitekim YÖK verilerine göre 2006-2007 eğitim öğretim yllında iki buçuk milyona yakın üniversite öğrencisi yüksek öğretime kayıtlı durumda iken bu sayı 2011-2012 eğitim öğretim yllında dört milyonu bulmuş ve 2015-2016 eğitim öğretim y1lında ise altı buçuk milyonu geçmiştir (Yüksek Öğretim Kurulu, 2016).

Üniversite öğrencisi olmak kendi içinde çeşitli uyum problemleriyle karşı karşısya kalmayı beraberinde getirmektedir (Özgüven, 1992). Mezun sayısının artmasıyla birlikte iş sahasında daralmalar yaşanmakta ve çeşitli istihdam sıkıntıları da ortaya çıkmaktadır. Aynı zamanda üniversite öğrencileri, gelişim dönemleri itibari ile ergenlik dönemi ile yetişkinlik dönemi arasında kalan çalkantılı bir geçiş evresi ile de baş etmektedir. Dolayısıyla üniversite öğrencilerinin pek çok alanda (iş alanı, başarı alanı, ilişki alanı.vb) problem çeşitliliğine sahip olduğu düşünülebilir. Bütün bu faktörler bir arada ele alındığında üniversite öğrencilerinin yaşadığı problemlerin anlaşılması ve bu problemlere yönelik çözüm önerilerinin sunulması hem genç nüfusun daha doyumlu ve üretken bir hayat sürmesi adına hem de toplumun gençlerden daha fazla verim alması adına önemlidir. Nitekim geçmiş dönemlerde üniversite öğrencilerinin problemlerini ele alan çeşitli çalışmalar yapılmıştır.

Özgüven (1992)' in yaptı̆̆1 çalışmada üniversite öğrencilerinin yaşadığ1 problemler incelenmiştir. Yapılan çalışma sonucu elde edilen bulgulara göre üniversite öğrencilerinin kimlik edinmeye dair çeşitli problemlerle birlikte, ilişki problemleri, iş bulmaya dair problemler, gelecek kayg1sı ve akademik problemler yaşadığ1 görülmüştür. Yine Özgüven (1989)'in yaptı̆̆1 bir başka çalışmada problem kaynakları ele alınmış ve akademik zoruluklar, geleceğe yönelik belirsizlikler, kişisel sebepler, ekonomik koşullar ve ilişkilere dair güçlüklerin üniversite öğrencilerinin yaşadığ1 olumsuz duygulara kaynaklık ettiği ortaya konmuştur.

Gizir (2005) ise yaptı̆̆ı çalışmada ODTÜ’de öğrenimini sürdüren son sınıf öğrencilerinin problemlerini ele almıştır. Bu çalışmada öğrencilerin sosyal, akademik ve mesleki olarak çeşitli problemlerinin olduğu ortaya çıkmıştır. Katılımcıların mesleki olarak; iş bulma, maddi açıdan uygun bir iş bulma, eğitim alınan alana göre iş bulma ve yeterince mesleki formasyona sahip olamama gibi problemler yaşadığı ortaya konmuştur. Bunun yanında katılımcılar hem kadın-erkek ilişkilerinin hem de arkadaşlık ilişkilerinin yüzeysel ve çıkara dayalı olduğunu söylemişlerdir. Bu araştırmada, yaşanan problemlerin fakülteye göre farklılık gösterdiği anlaşılmıştır. Buna göre eğitim fakültesi öğrencilerinin daha çok akademik, iktisadi ve idari bilimler fakültesi öğrencilerinin daha çok mesleki (iş bulma ve gelecek kaygısı), mimarlık fakültesi öğrencilerinin daha çok akademik ve sosyal, fen edebiyat fakültesi öğrencilerinin daha çok akademik ve mesleki (iş bulma ve gelecek kaygisı) ve mühendislik fakültesi öğrencilerinin daha çok sosyal, ilişkisel ve akademik problemlerinin olduğu görülmüştür.

Topkaya ve Meydan (2013)' da yaptığı araştırmada üniversite öğrencilerinin en çok duygusal problemlerle karşılaştığını ve bunu takiben romantik sorunlar, ekonomik sorunlar, akademik sorunlar, kişilikle ilgili sorunlar, uyum sorunları, aile ile ilgili sorunlar, arkadaşlarla ilgili sorunlar, madde kullanımına dair sorunlar ve cinsel sorunlar takip etmektedir. Bu araştırmaya göre bazı problem alanlarında cinsiyete göre farklılıklar bulunmuştur. Buna göre kadın öğrenciler erkeklere göre daha çok ilişki problemi yaşarken erkek öğrenciler kadın öğrencilere göre daha çok sigara ve madde kullanımı problemi yaşamaktadır.

Canbaz, Sünter, Aker ve Pekşen (2007)' tıp fakültesi son sınıf öğrencileri üzerinde yaptığ1 çalışmada tıp fakültesi öğrencilerinin mesleki problemlerden kaynaklanan bir kayg1 yaşadığı tespit edilmiştir. Buna göre tıp fakültesi öğrencilerinin uzamanlık alıp alamayacaklarına dair bir kaygıları olduğu bulunmuştur. Aynı zamanda iş güvencesinin olmuyor olması ve mesleki saygınlığın giderek azalması da tıp fakültesi son sınıf öğrencilerinin kayg1 kaynakları arasında bulunmuştur.

Yurt dışında yapılan araştırmalar da ülkemizde yapılan araştırmalara benzerlik göstermektedir. Schwitzer (1996) üniversite öğrencilerinin akademik, duygusal, mesleki ve ekonomik problemlerle karşı karşıya kaldığını söylemiştir. Bir başka araştırma da ise üniversite öğrencilerinin kişiler arası ilişkiler, aile çatışmaları ve akademik performans konularında sorun 
Bulut, S., \& Yıldırım, M. (2020). Öğretmen adaylarının problem alanları ve psikolojik belirtileri. Journal of Human Sciences, 17(2), 402-414. doi:10.14687/jhs.v17i2.4313

yaşadıklarını ve özellikle bu konularda yardım aradıklarını ortaya koymuştur (Oliveira, Dantas, Azevedo ve Banzato, 2008).

İncelenen araştırmalar sonucu görülmektedir ki üniversite dönemi kendine özgü çeşitli problem alanlarının içinde barındıran bir dönemdir (Özgüven, 1992). Nitekim araştırmalar üniversite öğrencilerinin mesleki, ilişkisel, sosyal ve ekonomik bir takım problemler yaşadığını ortaya koymaktadır. Yine bazı araştırma sonuçları yaşanan problemlerin bölüm ve cinsiyet gibi değişkenlere göre farklılık gösterdiğini ortaya koymaktadır (Gizir, 2005). Fakat eğitim fakültesi öğrencilerinin yaşadığı problem alanlarını ele alan çalışmaların oldukça az sayıda olduğu gözlenmektedir. Bu durum eğitim fakültesi öğrencilerinin yaşadığ1 problemlerin anlaşılması ve bu problemlerle ilgili politikaların geliştirilmesinde büyük bir bilgi eksikliğine sebep olmaktadır. Böylece bu çalışmada eğitim fakültesi öğrencilerinin yaşadığı problemler ve bu problemler sonucu ortaya çıkan psikolojik belirtiler araştırılmıştır.

\section{YÖNTEM}

$\mathrm{Bu}$ araştırma eğitim fakültesi öğrencilerinin yaşadığı problem alanlarını ve bu problem alanlarının psikolojik belirtiler olan etkisini belirlemeye yönelik betimsel türde ilişkisel tarama modeli ile gerçekleştirilen bir araştırmadır. Metnin bu bölümünde sırasıyla araştırma grubundan, veri toplama araçlarından, veri toplama işleminden ve verilerin analizinden bahsedilecektir.

\section{1. Araştırma Grubu}

Araştırma grubunu 2015-2016 eğitim öğretim yllında Abant İzzet Baysal Üniversitesi Eğitim Fakültesinde öğrenimine devam eden 121 lisans öğrencisi oluşturmaktadır. Katılımciların 77(\%63.6)'sini kadınlar 44(\%36.4)'ünü erkekler oluşturmaktadır. Örneklem grubunun 55(\%45.5)'i Rehberlik ve Psikolojik Danışmanlık Bölümünde, 43(\%35.5)'ü Sınıf Öğretmenliği Bölümünde ve 23(\%19)'ü Bilgisayar ve Öğrenim Teknolojileri Eğitimi Bölümünde öğrenimini sürdürmektedir.

\section{2. Veri Toplama Araçları}

Araştırmada veri toplama aracı olarak araştırmacı tarafindan literatür 1şığında oluşturulan kişisel bilgi formu ve öğrencilerin yaşamıs olabileceği en yaygın sorunlardan oluşan kısa bir anket hazırlanmış ve bunlarala beraber Belirti Tarama Testi(SCL-90) kullanılmıştır.

\section{2. 1. Belirti Tarama Testi (SCL-90)}

Derogotis tarafından 1976 yılında geliştirilen ölçme aracının Türkçe’ye uyarma çalışmaları Kılıç (1991) tarafindan yapilmıştır. Ölçek 10 alt boyuttan oluşmakta olup psikolojik belirtileri Ölçmektedir. Ölçek 10 alt boyut puanı ve 1 genel sağlı puanı vermektedir.

Ölçeğin test- tekrar test güvenirliliği incelenmiş ve Somatizasyon alt boyutu için .82, ObsesifKompulusif alt boyutu için .84, Kişiler Arası Duyarlllık alt boyutu için .79, Deprsyon alt boyutu için .78, Kayg1 alt boyutu için .78, Öfke ve Düşmanlık alt boyutu için .79, Fobik Anksiyete alt boyutu için .78, Paranoid alt boyutu için .63, Psikotizm alt boyutu için .73, Ek Skala (yemek yeme, uyku bozuklukları ve suçluluk duyguları gibi belirtiler) alt boyutu için .77 güvenilirlik katsayısına ulaşılmıştır. Aynı zamanda benzer bir yapıyı ölçen MMPI testi ile SCL-90 arasında ki korelasyonun .40 ile .59 arasında değiştiği gözlenmiştir. Elde edilen bulgular 1şığında ölçeğin geçerli ve güvenilir bir ölçme aracı olduğu söylenebilir.

\section{3. Veri Toplama İşlemi}

Araştırmanın örneklemini 2015-2016 Eğitim Öğretim Yllı Bahar Döneminde Abant İzzet Baysal Üniversite Eğitim Fakültesinde öğrenimini sürdüren 121 lisan öğrencisi oluşturmaktadır. Araştırma için kurumsal etik komiteden ve bölümlerden izin alındıktan sonra, ders saatlerinde derslere gidilerek, öğrencilere araştırmanın konusu ve gizlilik ilkesi kısaca anlatılmış ve gönüllü olanların katılımı ile araştırma gerçekleştirilmiştir. Anketler araştırmacılar tarafından bir ders saatinin başlangıcında yapılmış ve yaklaşık olarak 15 dakika kadar sürmüştür.

\section{4. Verilerin Analizi}

Elde edilen veriler SPSS 22.0 paket programında analiz edilmiştir. öncelikle veri setinin normalliği sınanmış ve yapılan istatistik analiz sonucu veri setinin normal dağıllım göstermediği 
Bulut, S., \& Yıldırım, M. (2020). Öğretmen adaylarının problem alanları ve psikolojik belirtileri. Journal of Human Sciences, 17(2), 402-414. doi:10.14687/jhs.v17i2.4313

anlaşılmıştır. Böylece verilerin analizinde parametrik olmayan analizler (Kruskall Wallis ve Mann Whitney U testleri) kullanılmıstır.

\section{BULGULAR}

$\mathrm{Bu}$ araştırmada eğitim fakültesi son sınıf öğrencilerinin yaşadığı problem alanlarının tespit edilmesi amaçlanmışır. Araştırmanın bir diğer amacı ise psikolojik belirtilerin; cinsiyet, bölüm ve yaşanılan problem türüne göre farklılaşıp farklılaşmadığını ortaya koymaktır. Bu bağlamda bulgular bölümünde, amaç doğrultusunda elde edilen sonuçlar tablolar halinde sunulacaktır.

Öncelikle katılımciların SCL-90'dan aldıkları puanlar incelenmiştir. Yapılan analiz sonucu elde edilen bulgular Tablo 1'de sunulmuştur.

\begin{tabular}{ccc}
\hline Tablo 1: SCL-90'a ve alt boyutlarna ait ortalama ve standart sapma değerleri(N=121) & \\
\hline SCL-90 & Ortalama & Standart Sapma \\
\hline Somatizasyon & 1,1018 &, 778 \\
OKB & 1,5612 &, 688 \\
Kişiler Aras1 Duyarlılık & 1,2255 &, 809 \\
Depresyon & 1,3940 &, 769 \\
Kayg1 & 1,0249 &, 767 \\
Öfke-Düşmanlık & 1,0712 &, 816 \\
Fobik Anksiyete &, 7268 &, 773 \\
Paronoid Düşünceler & 1,234 &, 898 \\
Psikotizm &, 7874 &, 715 \\
Ek Skala & 1,2734 &, 842 \\
Genel Sağlık & 1,1570 &, 673 \\
\hline
\end{tabular}

SCL-90 ve alt boyutlarına dair ortalama ve standart sapma değerleri Tablo 1'de gösterilmiştir. Buna göre üniversite öğrencilerinin aldıkları puanlar yüksekten düşüğe göre sıralandığında $O K B$, Depresyon, Ek Scala(yemek yeme, uyku bozuklukları ve suçluluk duyguları gibi belirtiler), Kişiler Arası Duyarlılık, Paranoid Düşünceler, Somatizasyon, Öfke-Düssmanlık, Kayg1, Psikotizm ve Fobik Anksiyete şeklinde olduğu görülmektedir. Örneklem grubunun Genel Sağlık ortalamas1 ise 1,1570'dir. SCL-90'n kriterlerine göre 0-1,5 puan arası puanlar normal kabul edilirken 1,5-2,5 aras1 yüksek ve 2,5-4 arası çok yüksek patoloji belirtisi göstermektedir (Dağ, 1991). Dolayısıyla örneklem grubunun $\mathrm{OKB}$ alt boyutu sınırda olmak kaydıyla yüksek değerler alırken diğer alt boyutlar normal seviyededir. Katılımcıların belirttikleri problem alanları Tablo 2'de gösterilmiştir.

\begin{tabular}{ccc}
\hline Tablo 2: katılimcılarn problem alanlarna göre frekanslarn ve yüzdeleri $(N=12)$ & \\
\hline Problem Alanı & Frekans & Yüzde \\
\hline Barınma & 2 & 1,7 \\
Romantik ilişkinin yokluğu & 6 & 5 \\
Romantik ilişkinin varlı̆̆1 & 5 & 4,1 \\
Gelecek kaygisı & 33 & 27,3 \\
Kpss kaygisı & 63 & 52,1 \\
Ailevi sorunlar & 9 & 7,4 \\
Akademik sorunlar & 3 & 2,5 \\
\hline
\end{tabular}

Tablo 2'de görüldüğü gibi en çok yaşanan sorunlar açısından katılımcılardan 2 kişi barınma ile ilgili sorunlar, 3 kişi akademi sorunlar, 5 kişi romantik ilişkisinden kaynaklanan sorunlar, 6 kişi romantik ilişkinin olmamasından kaynaklana sorunlar, 9 kişi ailevi sorunlar, 33 kişi gelecek kaygısına dayalı sorunlar ve 63 kişi KPSS’ye yönelik sorunlar yaşadığını belirtmişlerdir. 
SCL-90’a ait alt boyutların cinsiyete göre farklılıaşıp farklılaşmadığını ortaya koyabilmek adına Mann Whitney U testi uygulanmıştır. Elde dilen bulgular Tablo 3'de gösterilmiştir.

\begin{tabular}{|c|c|c|c|c|c|c|c|}
\hline & Gruplar & $\mathrm{N}$ & $\begin{array}{c}\text { Sira } \\
\text { Ortalamalar1 } \\
\end{array}$ & $\begin{array}{c}\text { Sira } \\
\text { Toplamlar }\end{array}$ & $\mathrm{u}$ & Z & $\mathrm{p}$ \\
\hline \multirow{2}{*}{ Somatizasyon } & Kadin & 77 & 61,68 & 4749,00 & \multirow{2}{*}{1642,00} & \multirow{2}{*}{,- 280} & \multirow{2}{*}{, 779} \\
\hline & Erkek & 44 & 59,82 & 2632,00 & & & \\
\hline \multirow{2}{*}{$\mathrm{OKB}$} & Kadın & 77 & 63,69 & 4904,00 & \multirow{2}{*}{1487,00} & \multirow{2}{*}{$-1,117$} & \multirow{2}{*}{,264 } \\
\hline & Erkek & 44 & 56,30 & 2477,00 & & & \\
\hline \multirow{2}{*}{$\begin{array}{c}\text { Kişiler Aras1 } \\
\text { Duyarlılık }\end{array}$} & Kadın & 77 & 60,82 & 4683,50 & \multirow{2}{*}{1680,50} & \multirow{2}{*}{,- 073} & \multirow{2}{*}{946} \\
\hline & Erkek & 44 & 61,31 & 2697,50 & & & \\
\hline \multirow{2}{*}{ Depresyon } & Kadin & 77 & 62,60 & 4820,00 & \multirow{2}{*}{1571,00} & \multirow{2}{*}{,- 663} & \multirow{2}{*}{, 507} \\
\hline & Erkek & 44 & 58,20 & 2561,00 & & & \\
\hline \multirow{2}{*}{ Kayg1 } & Kadin & 77 & 62,23 & 4791,50 & \multirow{2}{*}{1599,50} & \multirow{2}{*}{,- 510} & \multirow{2}{*}{,610 } \\
\hline & Erkek & 44 & 58,85 & 2589,50 & & & \\
\hline \multirow{2}{*}{ Öfke-Düşmanlık } & Kadın & 77 & 58,19 & 4480,50 & \multirow{2}{*}{1477,50} & \multirow{2}{*}{$-1,170$} & \multirow{2}{*}{,242 } \\
\hline & Erkek & 44 & 65,92 & 2900,50 & & & \\
\hline \multirow{2}{*}{ Fobik Anksiyete } & Kadin & 77 & 60,77 & 4679,50 & \multirow{2}{*}{1676,00} & \multirow{2}{*}{,- 095} & \multirow{2}{*}{,924 } \\
\hline & Erkek & 44 & 61,40 & 2701,50 & & & \\
\hline \multirow{2}{*}{$\begin{array}{l}\text { Paronoid } \\
\text { Düşünceler }\end{array}$} & Kadin & 77 & 57,95 & 4464,00 & \multirow{2}{*}{1459,00} & \multirow{2}{*}{$-1,269$} & \multirow{2}{*}{,204 } \\
\hline & Erkek & 44 & 66,34 & 2919,00 & & & \\
\hline \multirow{2}{*}{ Psikotizm } & Kadın & 77 & 58,40 & 4497,00 & \multirow{2}{*}{1494,00} & $-1,080$ & 280 \\
\hline & Erkek & 44 & 65,55 & 2884,00 & & & \\
\hline Ek Skala & Kadın & 77 & 57,64 & 4438,50 & 1435,00 & $-1,395$ & 163 \\
\hline & Erkek & 44 & 66,88 & 2942,50 & & & \\
\hline Genel Sŏ̌ll1 & Kadın & 77 & 60,06 & 4624,50 & 162450 & 391 & 606 \\
\hline Genici dagun & Erkek & 44 & 62,65 & 2756,50 & 1024,00 & ( & (2) \\
\hline
\end{tabular}

Yapılan Mann Whitney U testine göre SCL-90 ölçeğinin Kişiler Arası Duyarlılık, ÖfkeDüşmanlık, Fobik Anksiyete, Paronoid Düşüce, Psikotizm, Ek Skala, Somatizasyon, OKB ve Depresyon alt boyutlarından alınan puanlar cinsiyet değişkenine göre istatistiksel olarak anlamlı göstermemektedir.

SCL-90’a ait alt boyutların bölüme göre farklılık gösterip göstermediğini ortaya koyabilmek adına Kruskal Wallis testi uygulanmıştır. Elde edilen bulgular Tablo 4'de sunulmuştur. 
Bulut, S., \& Yıldıım, M. (2020). Öğretmen adaylarının problem alanları ve psikolojik belirtileri. Journal of Human Sciences, 17(2), 402-414. doi:10.14687/ihs.v17i2.4313

Tablo 4: SCL-90'dan alinan puanlarn bölïm deģ̧̆skenine göre değerlendirilmesine dair yapılan Kruskal Wallis Analizi

\begin{tabular}{|c|c|c|c|c|c|c|}
\hline & Gruplar & $\mathrm{N}$ & $\begin{array}{c}\text { Sira } \\
\text { Ortalamalar1 } \\
\end{array}$ & $\mathrm{Sd}$ & $\begin{array}{c}\text { Ki-Kare } \\
\text { değeri }\end{array}$ & $\mathrm{P}$ \\
\hline \multirow{3}{*}{ Somatizasyon } & BÖTE & 23 & 65,17 & \multirow{3}{*}{2} & \multirow{3}{*}{,405 } & \multirow{3}{*}{817} \\
\hline & PDR & 55 & 59,89 & & & \\
\hline & SNÖ & 43 & 60,19 & & & \\
\hline \multirow{3}{*}{$\mathrm{OKB}$} & BÖTE & 23 & 75,52 & \multirow{3}{*}{2} & \multirow{3}{*}{5,241} & \multirow{3}{*}{, 073} \\
\hline & PDR & 55 & 55,72 & & & \\
\hline & SNÖ & 43 & 59,99 & & & \\
\hline \multirow{3}{*}{ Kşişiler Arası Duyarlilık } & BÖTE & 23 & 72,13 & \multirow{3}{*}{2} & \multirow{3}{*}{3,644} & \multirow{3}{*}{,162 } \\
\hline & PDR & 55 & 61,15 & & & \\
\hline & SNÖ & 43 & 54,86 & & & \\
\hline \multirow{3}{*}{ Depresyon } & BÖTE & 23 & 65,13 & \multirow{3}{*}{2} & \multirow{3}{*}{1,078} & \multirow{3}{*}{, 583} \\
\hline & PDR & 55 & 61,65 & & & \\
\hline & SNÖ & 43 & 56,72 & & & \\
\hline \multirow{3}{*}{ Kayg1 } & BÖTE & 23 & 67,57 & \multirow{3}{*}{2} & \multirow{3}{*}{,998 } & \multirow{3}{*}{607} \\
\hline & PDR & 55 & 59,43 & & & \\
\hline & SNÖ & 43 & 59,50 & & & \\
\hline \multirow{3}{*}{ Öfke-Düssmanlık } & BÖTE & 23 & 70,87 & \multirow{3}{*}{2} & \multirow{3}{*}{2,254} & \multirow{3}{*}{,324 } \\
\hline & PDR & 55 & 57,94 & & & \\
\hline & SNÖ & 43 & 59,72 & & & \\
\hline \multirow{3}{*}{ Fobik Anksiyete } & BÖTE & 23 & 70,87 & \multirow{3}{*}{2} & \multirow{3}{*}{2,287} & \multirow{3}{*}{, $31 c$} \\
\hline & PDR & 55 & 59,02 & & & \\
\hline & SNÖ & 43 & 58,26 & & & \\
\hline \multirow{3}{*}{ Paronoid Düşünceler } & BÖTE & 23 & 70,04 & & & \\
\hline & PDR & 55 & 59,02 & 2 & 1,939 & ,397 \\
\hline & SNÖ & 43 & 58,26 & & & \\
\hline & BÖTE & 23 & 74,63 & & & \\
\hline Psikotizm & PDR & 55 & 56,65 & 2 & 4,441 & ,109 \\
\hline & SNÖ & 43 & 59,27 & & & \\
\hline & BÖTE & 23 & 74,91 & & & \\
\hline Ek Skala & PDR & 55 & 60,58 & 2 & 5,134 & ,070 \\
\hline & SNÖ & 43 & 54,09 & & & \\
\hline & BÖTE & 23 & 70,17 & & & \\
\hline Genel Sağlık & PDR & 55 & 58,99 & 2 & 1,945 & ,378 \\
\hline & SNÖ & 43 & 58,66 & & & \\
\hline
\end{tabular}

Tablo 4'de SCL-90'dan alınan puanların bölüm değişkenine göre farkllilk gösterip göstermediğine dair yapılan Kruskal Wallis analizi sonuçları görülmektedir. Yapılan analiz sonucununa göre SCL-90 ölçeğinin Kişiler Arası Duyarlılık, Öfke-Düşmanlık, Fobik Anksiyete, Paronoid Düşüce, Psikotizm, Ek Skala, Somatizasyon, OKB ve Depresyon alt boyutlarından alınan puanlar bölüm değişkenine göre istatistiksel olarak anlamlı göstermemektedir.

SCL-90'a ait alt boyutların problem alanına göre farklllık gösterip göstermediğini tespit edilebilmesi adına Kruska Wallis testi uygulanmıştır. Analiz sonucu elde edilen bulgular Tablo 5'de sunulmuştur. 
Bulut, S., \& Yıldıım, M. (2020). Öğretmen adaylarının problem alanları ve psikolojik belirtileri. Journal of Human Sciences, 17(2), 402-414. doi:10.14687/jhs.v17i2.4313

Tablo 5: SCL-90'dan alınan puanlarn problem alan değgşkenine göre değerlendirilmesine dair yapılan Kruskal Wallis Analizi

\begin{tabular}{|c|c|c|c|c|c|c|}
\hline & Gruplar & $\mathrm{N}$ & $\begin{array}{c}\text { Sira } \\
\text { Ortalamalar1 }\end{array}$ & $\mathrm{Sd}$ & $\begin{array}{c}\text { Ki-Kare } \\
\text { değeri }\end{array}$ & $\mathrm{P}$ \\
\hline \multirow{7}{*}{ Somatizasyon } & Barınma & 2 & 89,75 & \multirow{7}{*}{6} & \multirow{7}{*}{3,437} & \multirow{7}{*}{, 752} \\
\hline & $\begin{array}{l}\text { Romantik ilişskinin } \\
\text { yokluğu }\end{array}$ & 6 & 57,25 & & & \\
\hline & Romantik ilişkinin varlığ1 & 5 & 65,70 & & & \\
\hline & Gelecek kayg1s1 & 33 & 57,68 & & & \\
\hline & Kpss kaygis1 & 63 & 63,91 & & & \\
\hline & Ailevi sorunlar & 9 & 50,50 & & & \\
\hline & Akademik sorunlar & 3 & 48,33 & & & \\
\hline \multirow{7}{*}{$\mathrm{OKB}$} & Barınma & 2 & 86,00 & \multirow{7}{*}{6} & \multirow{7}{*}{6,041} & \multirow{7}{*}{,419 } \\
\hline & $\begin{array}{c}\text { Romantik ilişskinin } \\
\text { yokluğu }\end{array}$ & 6 & 35,08 & & & \\
\hline & Romantik ilişkinin varlı̆g1 & 5 & 65,70 & & & \\
\hline & Gelecek kayg1s1 & 33 & 63,24 & & & \\
\hline & Kpss kayg1s1 & 63 & 62,48 & & & \\
\hline & Ailevi sorunlar & 9 & 48,33 & & & \\
\hline & Akademik sorunlar & 3 & 70,50 & & & \\
\hline \multirow{7}{*}{$\begin{array}{l}\text { Kşişiler Aras1 } \\
\text { Duyarll11k }\end{array}$} & Barınma & 2 & 97,25 & \multirow{7}{*}{6} & \multirow{7}{*}{3,110} & \multirow{7}{*}{,795 } \\
\hline & $\begin{array}{c}\text { Romantik iliş̧kinin } \\
\text { yokluğu }\end{array}$ & 6 & 59,33 & & & \\
\hline & Romantik ilişkinin varlı̆̆1 & 5 & 72,20 & & & \\
\hline & Gelecek kayg1s1 & 33 & 60,52 & & & \\
\hline & Kpss kayg1s1 & 63 & 59,79 & & & \\
\hline & Ailevi sorunlar & 9 & 55,56 & & & \\
\hline & Akademik sorunlar & 3 & 68,67 & & & \\
\hline \multirow{7}{*}{ Depresyon } & Barınma & 2 & 83,00 & \multirow{7}{*}{6} & \multirow{7}{*}{8,746} & \multirow{7}{*}{,188 } \\
\hline & $\begin{array}{l}\text { Romantik ilişskinin } \\
\text { yokluğu }\end{array}$ & 6 & 54,67 & & & \\
\hline & Romantik ilişkinin varlı̆g1 & 5 & 76,80 & & & \\
\hline & Gelecek kayg1s1 & 33 & 58,53 & & & \\
\hline & Kpss kaygis1 & 63 & 60,07 & & & \\
\hline & Ailevi sorunlar & 9 & 58,89 & & & \\
\hline & Akademik sorunlar & 3 & 109,67 & & & \\
\hline \multirow{7}{*}{ Kayg1 } & Barınma & 2 & 89,50 & \multirow{7}{*}{6} & \multirow{7}{*}{3,501} & \multirow{7}{*}{, 744} \\
\hline & $\begin{array}{l}\text { Romantik ilişsinin } \\
\text { yokluğu }\end{array}$ & 6 & 48,92 & & & \\
\hline & Romantik ilişkinin varlığ1 & 5 & 59,70 & & & \\
\hline & Gelecek kaygis1 & 33 & 63,05 & & & \\
\hline & Kpss kaygis1 & 63 & 61,71 & & & \\
\hline & Ailevi sorunlar & 9 & 48,39 & & & \\
\hline & Akademik sorunlar & 3 & 68,83 & & & \\
\hline \multirow{5}{*}{,Öfke-Düşmanlık } & Barınma & 2 & 90,25 & \multirow{5}{*}{6} & \multirow{5}{*}{3,688} & \multirow{5}{*}{,719 } \\
\hline & $\begin{array}{l}\text { Romantik ilişkinin } \\
\text { yokluğu }\end{array}$ & 6 & 56,17 & & & \\
\hline & Romantik ilişkinin varlığ1 & 5 & 66,30 & & & \\
\hline & Gelecek kayg1s1 & 33 & 59,12 & & & \\
\hline & Kpss kayg1s1 & 63 & 62,73 & & & \\
\hline
\end{tabular}


Bulut, S., \& Yıldıım, M. (2020). Öğretmen adaylarının problem alanları ve psikolojik belirtileri. Journal of Human Sciences, 17(2), 402-414. doi:10.14687/jhs.v17i2.4313

\begin{tabular}{|c|c|c|c|c|c|c|}
\hline & Ailevi sorunlar & 9 & 46,33 & & & \\
\hline & Akademik sorunlar & 3 & 70,67 & & & \\
\hline \multirow{7}{*}{ Fobik Anksiyete } & Barınma & 2 & 92,25 & \multirow{7}{*}{6} & \multirow{7}{*}{3,334} & \multirow{7}{*}{,766 } \\
\hline & $\begin{array}{l}\text { Romantik ilişkinin } \\
\text { yokluğu }\end{array}$ & 6 & 59,25 & & & \\
\hline & Romantik ilişkkinin varlığ1 & 5 & 55,70 & & & \\
\hline & Gelecek kayg1s1 & 33 & 62,83 & & & \\
\hline & Kpss kaygis1 & 63 & 61,89 & & & \\
\hline & Ailevi sorunlar & 9 & 47,50 & & & \\
\hline & Akademik sorunlar & 3 & 54,17 & & & \\
\hline \multirow{7}{*}{$\begin{array}{l}\text { Paronoid } \\
\text { Düşünceler }\end{array}$} & Barınma & 2 & 93,25 & \multirow{7}{*}{6} & \multirow{7}{*}{4,562} & \multirow{7}{*}{,766 } \\
\hline & $\begin{array}{c}\text { Romantik ilişkinin } \\
\text { yokluğu }\end{array}$ & 6 & 51,83 & & & \\
\hline & Romantik ilişkinin varlığ1 & 5 & 77,10 & & & \\
\hline & Gelecek kaygis1 & 33 & 59,80 & & & \\
\hline & Kpss kayg1s1 & 63 & 58,90 & & & \\
\hline & Ailevi sorunlar & 9 & 63,00 & & & \\
\hline & Akademik sorunlar & 3 & 82,17 & & & \\
\hline \multirow{7}{*}{ Psikotizm } & Barınma & 2 & 103,50 & \multirow{7}{*}{6} & \multirow{7}{*}{8,563} & \multirow{7}{*}{,601 } \\
\hline & $\begin{array}{c}\text { Romantik ilişkinin } \\
\text { yokluğu }\end{array}$ & 6 & 76,83 & & & \\
\hline & Romantik ilişkinin varlığ1 & 5 & 79,80 & & & \\
\hline & Gelecek kaygis1 & 33 & 62,82 & & & \\
\hline & Kpss kayg1s1 & 63 & 54,96 & & & \\
\hline & Ailevi sorunlar & 9 & 59,56 & & & \\
\hline & Akademik sorunlar & 3 & 80,83 & & & \\
\hline \multirow{7}{*}{ Ek Skala } & Barınma & 2 & 101,50 & \multirow{7}{*}{6} & \multirow{7}{*}{6,024} & \multirow{7}{*}{,420 } \\
\hline & $\begin{array}{c}\text { Romantik ilişsinin } \\
\text { yokluğu }\end{array}$ & 6 & 58,00 & & & \\
\hline & Romantik ilişkinin varlığ1 & 5 & 72,20 & & & \\
\hline & Gelecek kaygis1 & 33 & 58,91 & & & \\
\hline & Kpss kayg1s1 & 63 & 59,62 & & & \\
\hline & Ailevi sorunlar & 9 & 54,89 & & & \\
\hline & Akademik sorunlar & 3 & 91,67 & & & \\
\hline \multirow{7}{*}{ Genel Sağlık } & Barınma & 2 & 95,00 & \multirow{7}{*}{6} & \multirow{7}{*}{4,286} & \multirow{7}{*}{,638 } \\
\hline & $\begin{array}{c}\text { Romantik ilişskinin } \\
\text { yokluğu }\end{array}$ & 6 & 55,42 & & & \\
\hline & Romantik ilişkinin varlığ1 & 5 & 70,60 & & & \\
\hline & Gelecek kaygis1 & 33 & 59,88 & & & \\
\hline & Kpss kayg1s1 & 63 & 61,17 & & & \\
\hline & Ailevi sorunlar & 9 & 48,83 & & & \\
\hline & Akademik sorunlar & 3 & 78,67 & & & \\
\hline
\end{tabular}

Yapılan analiz sonucununa göre SCL-90 ölçeğinin Kişiler Arası Duyarlılık, Öfke-Düşmanlık, Fobik Anksiyete, Paronoid Düşüce, Psikotizm, Ek Skala, Somatizasyon, OKB ve Depresyon alt boyutlarından alınan puanlar problem alanına göre istatistiksel olarak anlamlı göstermemektedir.

Dolayısıyla SCL-90'in alt boyutları yaşanan problem alanına göre anlamlı düzeyde farklılaşmamaktadır. 
Bulut, S., \& Yıldırım, M. (2020). Öğretmen adaylarının problem alanları ve psikolojik belirtileri. Journal of Human Sciences, 17(2), 402-414. doi:10.14687/jhs.v17i2.4313

\section{TARTIŞMA VE SONUÇ}

$\mathrm{Bu}$ araştırmada eğitim fakültesi öğrencilerinin yaşadığı problem alanları tespit edilmeye çalışılmış ve aynı zamanda öğrencilerin SCL-90’a ait alt testlerden aldıkları puanların bölüm, cinsiyet ve yaşanılan problem alanına göre farklılık gösterip göstermediği ele alınmıştır.

Yapılan istatistiksel analizler sonucu eğitim fakültesi öğrencilerinin en çok yaşadığı problem alanının KPSS kayg1sı olduğu ve bunu takiben sırasıyla gelecek kaygısı, ailevi sorunlar, romantik ilişkinin olmamasına dair sorunlar, romantik ilişkinin olmasına dair sorunlar, akademik sorunlar ve barınmaya dair sorunlar olduğu görünmüştür.

Eğitim fakültesi son sınıf öğrencilerinin temel problem alanı olarak ortaya koyduğu KPSS kaygısı ve gelecek kaygısı beklenen bir sonuç olarak karşımıza çıkmaktadır. Son yıllarda Milli Eğitim Bakanlığı KPSS yoluyla öğretmen ataması yapma konusunda çeşitli değişikliler yapılmıştır. Bu bağlamda "Genel Kültür ve Genel Yetenek" ve "Eğitim Bilimleri" sınavlarına ek olarak öğretmen adaylarının kendi alanlarına dair bilgilerini ölçmek üzere "Alan Bilgisi" sınavını uygulamaya başlamıştır. Aynı zamanda yazılı sınav dışında sözlü mülakat uygulaması başlatılmıştır. Böylece Milli Eğitim Bakanlığı bünyesine atanma şartlarının zorlaştı̆̆1 ve öğretmen adayları için KPSS'nin daha çok emek gerektiren bir sınav halini aldığı söylenebilir. Ülkemizde eğitim fakültesi mezunlarının büyük bir bölümü devlet okullarında istihdam edilmektedir. Dolayısıyla KPSS'den yeterli puan alamamak ve atanamamak üniversite öğrencileri için büyük bir kayg1 kaynağı olabilir. Nitekim yapılan bir araştırmada eğitim fakültesinden öğrenim gören lisans son sınıf öğrencilerinden KPSS hakkında bir resim yapmaları istenmiştir. Resimler incelendiğinde lisans öğrencilerinin KPSS'yi stress ve kaygiya sebep olan, diğer yaşam olaylarına engel oluşturan ve belirsizlikler barındıran bir süreç olarak algıladıkları anlaşılmıştır (Güven ve Dak, 2017). Yine Şahin (2011)'in eğitim fakültesi öğrencileri ile yaptı̆̆ı çalışmada öğretmen adayları, atanamadıkları durumda hayatlarının çok olumsuz etkileneceklerini belirtmiştir. Benzer şekilde Ceyhan (2004) da öğretmen adayları ile yaptığ1 çalışmada iş bulma beklentisi düşük olan öğretmen adaylarının umutsuzluk düzeylerinin daha yüksek olduğunu bulmuştur. Dolayısıyla eğitim fakültesi öğrencileri mezun olduktan sonra istihdam edilip edilmeyeceğine dair bir belirsizlik yaşadığı düşünülebilir. Bu durum, öğretmen adaylarının hem KPSS hem de gelecek kaygısı duymasına sebep olabilir. Bunun yanında ülkemizde yapılan bazı çalışmalara bakıldığında; Kaya ve Varol (2004) iş bulama endişesi yaşayan ilahiyat fakültesi öğrencilerinin kayg1 düzeylerinin daha yüksek olduğu bulmuştur. Benzer şekilde yüksek öğretim düzeyinde turizm eğitimi almakta olan öğrencilerin de iş bulamama endişesi ile gelecek kaygıs1 duyduğu literatür bulguları arasındadır (Baltacı, Üngören, Avsallı ve Demirel, 2012). Dursun ve Aytaç (2009)'n yaptığ1 çalışmada mühendislik fakültesi öğrencileri, ziraat fakültesi öğrencileri ve iktisadi ve idari bilimler fakültesi öğrencileri de örnekleme alınmış ve bu bölümlerin de iş bulma konusunda kaygı yaşadıkları tespit edilmiştir. Dolayısı ile iş bulma endişesi sonucu yaşanan gelecek kaygısının eğitim fakültesi öğrencilerine özgü olmadığı, bu durumun diğer bölümlerde öğrenim gören üniversite öğrencileri için de geçerli olduğu görülmektedir. Nitekim bazı araştırmacılar gelecek kaygısının üniversite öğrencilerinde en çok yaşanan problem arasında olduğuna vurgu yapmıştır (Tayfun ve Korkmaz, 2016; Yaşar ve Turgut, 2020)

Uluslararası düzeyde yapılan diğer bazı araştırmalar da bu durumun ülkemize özgü olmadığını göstermektedir. Yapılan araştırmalar üniversiteden yeni mezun olan öğrencilerin kariyer yapma ve iş bulma konularında problem yaşadıklarını ortaya koymaktadır (Abel, Deitz ve Su, 2014; Aluede, Imhonde ve Eguavoen; 2006; Lacković-Grgin, 2018; Li, Whalley ve Xing, 2014). Sonuç olarak iş bulmaya ve geleceğe dair kayg1 gütme ülke yada meslek fark etmeksizin üniversite öğrencilerinin gelişimsel olarak yaşadığı bir kriz olarak değerlendirilebilir.

Elde edilen bulgulardan bir diğeri ise öğretmen adayların SCL-90'dan aldıkları puanların cinsiyete göre faklılık göstermediği yönündedir. Benzer şekilde Akdur (2014) da yaptığı çalışmada cinsiyetin psikolojik belirtileri yordamadığını tespit etmiştir. Kartal, Çetinkaya ve Turan (2009)'da psikolojik belirtilerin cinsiyete göre farklılaşmadığını söylemektedir. Buna karşı psikolojik belirtileri; deprem yaşantısı (Aksaray, 2006), çocukluk çağı istismarı (Barker-Collo ve Read, 2011), ebeveyn tutumuları (Soygüt ve Çakır, 2009), sosyal destek (Doğan, 2008) ve bağlanma stilleri (Ergin ve Dağ, 
Bulut, S., \& Yıldırım, M. (2020). Öğretmen adaylarının problem alanları ve psikolojik belirtileri. Journal of Human Sciences, 17(2), 402-414. doi:10.14687/jhs.v17i2.4313

2013) gibi değişkenlerle ele alan çalşmalar psikolojik belirtilerin bu tür psikolojik ve sosyal değişkenlerle ilişkili olduğunu ortaya koymaktadır. Dolayısı ile psikolojik belirtilerin cinsiyet değişkeninden değil de diğer bazı psikolojik ve sosyal değişkenlerden etkilendiği söylenebilir.

Son olarak SCL-90'a ait alt boyutların bölüme (SNÖ-PDR-BÖTE) göre farklillk göstermediği görülmüştür. Yani SNÖ, PDR ve BÖTE lisans programlarında öğrenimini sürdüren üniversite son sınıf öğrencilerinin SCL-90’a ait alt boyutlardan aldıkları puanlar birbirleri ile benzerlik göstermektedir. Bu durumu ilgili lisans programlarının istihdam olanaklarının benzer olması ile ilgili olabilir. SNÖ, PDR ve BÖTE lisans programı mezunları daha çok Milli Eğitim Bakanlığ1 bünyesinde istihdam edilmektedir. Yıllar içinde ilgili bölüm mezunlarının sayısı artmış ve dolayısı ile istihdam alanı daralmıştır. Buna rağmen PDR, BÖTE ve SNÖ branşlarına verilen kadro sayısı 100'e yakın branş arasında illk 20'de yer almaktadır (MEB, 2016). Bu durum SNÖ, PDR ve BÖTE branşlarının benzer istihdam olanaklarına sahip olduğunu göstermektedir.

\section{KAYNAKÇA}

Abel, J. R., Deitz, R., \& Su, Y. (2014). Are recent college graduates finding good jobs? Current Issues in Economics and Finance, 20(1).

Akdur, S. (2014). Kişilik özellikleri ile psikolojik belirtiler arasındaki ilişkide kişilerarası ilişki tarzları ve mizah tarzlarının aracı rolü. Yaymlanmamış Yükesek Lisans Tezi. Ankara Üniversite, Sosyal Bilimler Enstitüsü. Ankara.

Aksaray, G., Kortan, G., Erkaya, H., Yenilmez, C.., \& Kaptanoğlu, C. (2006). Gender differences in psychological effect of the August 1999 earthquake in Turkey. Nordic journal of psychiatry, 60(5), 387-391.

Aluede, O., Imhonde, H., \& Eguavoen, A. (2006). Academic, career and personal needs of Nigerian university students. Journal of Instructional Psychology, 33(1), 50-58.

Barker-Collo, S., \& Read, J. (2011). The roles of gender and coping styles in the relationship between child abuse and the SCL-90-R subscales 'psychoticism'and 'paranoid ideation'. New Zealand Journal of Psychology, 40(3), 30-40.

Baltaci, F., Üngüren, E., Avsalli, H., \& Demirel, H. N. (2012). Turizm Eğitimi Alan Öğrencilerin Eğitim Memnuniyetlerinin ve Geleceğe Yönelik Bakış Açılarının Belirlemesine Yönelik Bir Araştırma. Uluslararası Alanya İ̧letme Fakültesi Dergisi, 4(1).

Canbaz, S., Sünter, A. T., Aker, S., \& Pekşen, Y. (2007). Tıp fakültesi son sınıf öğrencilerinin kayg1 düzeyi ve etkileyen faktörler. Genel Tip Dergisi, 17(1), 15-19.

Ceyhan, A. A. (2004). Ortaöğretim alan öğretmenliği tezsiz yüksek lisans programına devam eden öğretmen adaylarının umutsuzluk düzeylerinin incelenmesi. Sosyal Bilimler Dergisi, 1

Dağ, I. (1991). Belirti Tarama Listesi (Scl-90-R)'nin Üniversite Öğrencileri için güvenirliği ve geçerliği. Türk Psikiyatri Dergisi.

Doğan, T. (2008). Psikolojik belirtilerin yordayıcısı olarak sosyal destek ve iyilik hali. Türk Psikolojik Damısma ve Rebberlik. Dergisi, 3(30), 30-44.

Dursun, S., \& Aytaç, S. (2009). Üniversite öğrencileri arasında işsizlik kayg1sı. Uludağ Üniversitesi İktisadi ve İdari Bilimler Fakültesi Dergisi, 28(1), 71-84.

Epçaçan, C. (2016). Öğretmen adaylarının kpss ve öğretmenlik atamaları hakkındaki görüssleri. Electronic Turkish Studies, 11(3).

Ergin, B. E., \& Dağ, İ. (2013). Kişilerarası problem çözme davranışları, yetişkinlerdeki bağlanma yönelimleri ve psikolojik belirtiler arasındaki ilişkiler. Anatolian Journal of Psychiatry, 14, 3645

Gizir, C. A. (2005). Orta Doğu Teknik Üniversitesi son sınıf öğrencilerinin problemleri üzerine bir çalışma. Mersin Üniversitesi Ë̆gitim Fakülltesi Dergisi,1(2).

Güven, S. ve Dak, G. (2017). Öğretmen adaylarının Kamu Personel Seçme Sınavına (KPSS) ilişkin oluşturdukları görsel metaforlar. Eğitim ve Insani Bilimler Dergisi: Teori ve Uygulama, 8(15), 216. 
Bulut, S., \& Yıldırım, M. (2020). Öğretmen adaylarının problem alanları ve psikolojik belirtileri. Journal of Human Sciences, 17(2), 402-414. doi:10.14687/jhs.v17i2.4313

Kaya, M. \& Varol, K. (2004). İlahiyat fakültesi öğrencilerinin durumluk-sürekli kayg1 düzeyleri ve kayg1 nedenleri (Samsun örneği). Ondokuz. Mayıs Üniversitesi Ilabiyat Fakïltesi Dergisi, 17(17), $31-63$

Kartal, A., Çetinkaya, B., \& Turan, T. (2009). Sağllk yüksekokulu öğrencilerinde ruhsal belirtilerin taranmas1. TAF Preventive Medicine Bulletin, 8(2), 161-166.

Lacković-Grgin, K. (2018). Some psychological consequences of unemployment of young graduates. Papers on Philosophy, Psychology, Sociology and Pedagogy, 32(9).

Li, S., Whalley, J., \& Xing, C. (2014). China's higher education expansion and unemployment of college graduates. Cbina Economic Review, 30, 567-582.

Kılıç, M. (1991). Belirti Tarama Listesi (SCL-90-R)'nin Geçerlilik ve Güvenirliği.Türk Psikolojik Danısma ve Rebberlik Dergisi, 1(2), 45-52.

Milli Eğitim Bakanlığı, (2016, Ekim). Öğretmenlik Atamalar Sonucu Olusan Minimum Puanlar. bttp://personel.meb.gov.tr/ sayisal veriler.asp? ID $=207$

Oliveira, M. L. C. D., Dantas, C. D. R., Azevedo, R. C. S. D., \& Banzato, C. E. M. (2008). Demographics and complaints of university students who sought help at a campus mental health service between 1987 and 2004. Sao Paulo Medical Journal, 126(1), 58-62.

Özgüven, İ. E. (1992). Üniversite öğrencilerinin sorunlar1 ve baş etme yollar1. Hacettepe Üniversitesi Ë̈itim Fakültesi Dergisi, 7(7).

Özgüven, E. (1988). Yurtkur yurtlarında barınan öğrencilerin beklenti ve problemleri. Ankara: Yüksek. Ögretim Kredi ve Yurtlar Kurumu Genel Müdürlï̈̆̈̈.

Schweitzer, R. D. (1996). Problems and awareness of support services among students at an urban

Australian university. Journal of American College Health,45(2), 73-77

Soygüt, G., \& Çakır, Z. (2009). Ebeveynlik biçimleri ile psikolojik belirtiler arasındaki ilişkilerde kişilerarası şemaların aracı rolü: Şema odaklı bir bakış. Türk Psikiyatri Dergisi, 20(2), 144152.

Şahin, İ. (2011). Öğretmen adaylarının öğretmen istihdamı ve mesleki geleceklerine ilişkin görüşleri. Kuram ve Uygulamada Egitim Bilimleri, 11(3), 1167-1184.

Tayfun, A. N. T., \& Korkmaz, A. (2016). Üniversite öğrencilerinde işsizlik kaygısı: süleyman demirel üniversitesi öğrencileri üzerinde bir araştırma. Mehmet Akif Ersoy Unniversitesi Sosyal Bilimler Enstitüsü Dergisi, 8(17), 534-558.

Yaşar, O. M., \& Turgut, M. (2020). Unemployment anxiety of last year college students. Cypriot Journal of Educational Sciences, 15(1), 56-64.

Yüksek Öğretim Kurulu. Ÿ̈̈ksek. Öğretim Bilgi Yönetim Sistemi. https://istatistik.yok.gov.tr/ Erişim Tarihi: 21.10 .2016

\section{Extended English Abstract}

Turkey has a large number of young population. Especially, in recent years the number of university and university students has dramatically increased. In 2015-2016 educational year, the number of university students has reached over 6.5million (Higher Education Council, 2016).

University students face some specific adaptation problems (Özgüven, 1999). As the number of graduates number increases, it becomes more difficult to find jobs. At the same time, university students go through developmental transitions from adolescents to young adulthood and they have to deal with other requirements and responsibilities. Therefore, it is important to examine university students' problems since they are being expected to be a productive citizen in future society. There are some previous studies investigated college students' problems.

Özgüven (1992) found that university students mostly experience identity problems, relation problems, problems associated with job search, anxiety about future, and academic problems. It seems that academic difficulties, personal problems, relational problems and unclear future expectations are mostly occupy their agendas. In another study Giriz (2005) reported some problems as follows; social, academic and job search, good paying jobs, finding jobs that fits their 
Bulut, S., \& Yıldırım, M. (2020). Öğretmen adaylarının problem alanları ve psikolojik belirtileri. Journal of Human Sciences, 17(2), 402-414. doi:10.14687/jhs.v17i2.4313

educational background, and lack of preparation for their professions. On the other hand, Topkaya and Meydan (2013) identified, emotional problems, romantic problems, economic difficulties, academic problems, problems with their own personalities, adaptation problems, problems with family and friends, substance abuse, and sexual problems as the most commonly observed problems. Similar difficulties also experienced by medical students. Canbaz, Stüner, Aker and Pekşen (2007) conducted a study with last year medical students. They mostly reported difficulties about their future medical residency, decreasing respect to their job, and lack of safeties in their job.

Research conducted in other counties had similar results with Turkey. Schwitzer (1996) reported that university students face academic, emotional, financial and professional difficulties. In another research, Olivernia, Dantas, Azeveda and Banzato (2008) found that university students experience interpersonal relationship problems, family conflicts and difficulties in academic performance and especially seek help in these areas.

Research shows that university period has specific problems (Özgüven, 1992). Most of the research has repeatedly reported professional concerns, relationship, social and economic problems for the college age students. At the same time, some research found that some problems may differ according to departments and gender (Griz, 2005). However, very little research study investigated students attending college of education.

It is not very well known that what kind of problems teacher candidates experiences when they are studying in college. This also negatively effects the development of professional solutions and policy development for teacher education. Therefore, this study focused on the problems and psychological symptoms of the college of education students who are teacher candidates.

\section{Methods:}

The purpose of this study is to investigate the problems of the university students and because of these possible psychological symptoms. It is designed as a descriptive study and nonparametrical tests are utilized in data analysis. SPSS 22 statistical package was used in data process.

\section{Participants:}

The participants of the study were 121 undergraduate sophomore students attending Abant İzet Baysal University, College of Education in the 2015-2016 academic year. Participants consisted of 77 (\% 63.3) female and 44 (36.4) male students. The sample composed of $55(\% 45)$ guidance and counseling students, 43 (\% 35) elementary school teaching, and 23 (\% 19) computer teaching and technology teaching teacher candidates.

\section{Instruments:}

The researcher developed a short survey focused on the most common problems that college students face and Symptom Check List (SCL-90) utilized for screening for possible problems.

Symptom Cheek List (SCL-90). Originally, Deregotis (1976) develop this instrument. Kulıç (1991) did adaptation studies. The instrument has 10 subscales and each one specifically measure a distinct psychological symptoms and has a general total health scale.

\section{Data Analysis:}

Permission was received from institutional review board and related departments. The survey forms were distributed in class time. Students were voluntarily participated for this research and did not price any or credit. It usually took 10 minutes to fill out the questionnaires. Confidentiality and anonymity was granted and survey forms were shredded after entering the data in the computer. The data were processed with SPSS 22 package program. First, the data is tested for normality assumptions, which the results did not reveal a normal distribution. Therefore, Kruskall Wallis and Mann Whitney U nonparametric tests were run for data analysis.

\section{Results:}

As shown in table 1, when it is listed from high to low, obsessive-compulsive symptoms, depression, additional scale (eating, sleep and guilt), sensitivity in interpersonal relations, paranoid ideas, somatization, anger-hostility, anxiety, psichotizm, and phobic anxiety followed respectively. 
Bulut, S., \& Yıldırım, M. (2020). Öğretmen adaylarının problem alanları ve psikolojik belirtileri. Journal of Human Sciences, 17(2), 402-414. doi:10.14687/jhs.v17i2.4313

General health scale score for the whole sample was found to be 1.1. According to the evaluation criteria of the scale, scores between 0-1.5 is accepted normal, 1.5-2.5 high, and 2.5-4 considered high and pathological symptoms (Dağ, 1991). Therefore, only obsessive-compulsive symptoms were in borderline score, the rest of the sub-scale did not reveal any significant level of psychological symptoms.

The most common problems that university students experienced, as it was shown in table 2, 2 participants reported problems related with accommodation, 3 academic problems, 5 problems in their romantic relationships, 6 lack of romantic relationships, 9 family problems and conflicts, 33 anxiety for future, and 63 concerns about upcoming KPSS exam.

Mann Whitney $U$ test was utilized to test the effects of gender. Table 3 shows that male students outscored female students in interpersonal sensitivity, anger-hostility, phobic anxiety, paranoid ideation, psychotizm and additional scale whereas, female students scored higher in somatization, obsessive compulsive, and depression subscales. Differences were not observed all of the subscales; therefore, female and male student's psychological symptoms did not reveal any statistically significant results.

Kruskal Wallis tests were run to test statistical differences among departments in SCL-90 subscales. As it is reported in table 4, computer technology teaching candidate student has scored higher in all of subscales than the counseling and elementary school departments. But again the difference did not reach statistically significant level.

SCL-90's subscales were tested according to the student's problem groups. Kruskal Wallis is used to test the differences. Table 5 , shows the findings. Students, who has different type of problems, did not significantly differed in SCL-90's subscales.

\section{Discussions:}

The results reveal that students in college of education most often experience anxiety about the upcoming KPSS exams. This was followed by future anxiety, family problems, lack of romantic relationships, problems in romantic relationships, academic problems and accommodation problems.

The problem of KPSS exams and future anxiety is kind of expected results. The Ministry of Education requires a nation-wide competitive exam for personnel selection. Furthermore, in recent years the test become very difficult and requires an additional "area" test as well. Since college of education, students mostly seek governmental jobs upon graduation and the test becomes gradually more competitive; therefore, the stress level of students increased dramatically. Study done by Şahin (2011) with college of education students show that students believe that when they do not get jobs, their life will be negatively affected. Similarly, Ceyhan (2004) study with teacher candidates, when the teacher candidate's expectations about finding job decrease, their hopelessness increased. Thus, there is an indifferent situation about their future carrier expectations. Similar results also found with students in Divinity Faculty students (Kaya \& Varol, 2004). Dursun and Aytaç (2009) also reported high anxiety and negative expectations about future in engineering, business and agriculture departments' students.

It seems that anxiety about finding job is not only characteristics of education faculty students' problems. Students in other departments and faculties also experience similar difficulties, stress and anxiety. Most importantly, this is not only characteristics of Turkey but European and American students repeatedly reported also similar results.

The results shows that career counseling and personal counseling are also important in higher education. Students may receive counseling and guidance when they start university so that they can develop more realistic future expectations and they can plan their career in early days of college. This also makes career counseling very important aspects of college life. The results will help professional to understand and serve better to their college students. 